Article

\title{
Controlled Growth of LDH Films with Enhanced Photocatalytic Activity in a Mixed Wastewater Treatment
}

\author{
Zhongchuan Wang ${ }^{1}$, Pengfei Fang ${ }^{1}$, Parveen Kumar ${ }^{2} \mathbb{D}$, Weiwei Wang ${ }^{1, *}$, Bo Liu ${ }^{1,2, *}$ and \\ Jiao $\mathrm{Li}^{1}$ \\ 1 School of Material Science and Engineering, Shandong University of Technology, Zibo 255000, China; \\ wangzhongchuan1994@163.com (Z.W.); 17864373857@163.com (P.F.); haiyan9943@163.com (J.L.) \\ 2 Laboratory of Functional Molecular and Materials, School of Physics and Optoelectronic Engineering, \\ Shandong University of Technology, Zibo 255000, China; kumar@sdut.edu.cn \\ * Correspondence: wangweiwei@sdut.edu.cn (W.W.); liub@sdut.edu.cn (B.L.); \\ Tel.: +86-15689078202 (W.W.); +86-533-2783909 (B.L.)
}

Received: 15 April 2019; Accepted: 17 May 2019; Published: 28 May 2019

\begin{abstract}
Due to multiple charge transport pathways, adjustable layer spacing, compositional flexibility, low manufacturing cost, and absorption of visible light, layered double hydroxides (LDHs) are a promising material for wastewater treatment. In this study, LDH films and Fe-doped LDH films with different metal ions ( $\mathrm{Ni}, \mathrm{Al}, \mathrm{Fe})$ on the surface of conductive cloth were successfully prepared and applied for the photocatalytic degradation of wastewater containing methyl orange and Ag ions under visible-light irradiation. The chemical state of Fe ions and the composition of LDHs on methyl orange photodegradation were investigated. The experimental results showed that LDH films exhibited high photocatalytic activity. The photocatalytic activity of LDH films on methyl orange improved in the mixed wastewater, and the Fe-doped NiAl-LDH films exhibited best visible-light photocatalytic performance. The analysis showed that Ag ions in the mixed wastewater were reduced by the LDH films and subsequently deposited on the surface of the LDH films. The Ag nanoparticles acted as electron traps and promoted the photocatalytic activity of the LDH films on methyl orange. Thus, we have demonstrated that prepared LDH films can be used in the treatment of mixed wastewater and have broad application prospects in environmental remediation and purification processes.
\end{abstract}

Keywords: LDHs; film; mixed wastewater; photocatalytic activity

\section{Introduction}

Heavy metal ions and organic compounds are often discharged together during many industrial processes such as metal finishing, petroleum refining, and leather tanning and finishing, which indicates that the coexistence of heavy metal ions and organic compounds in wastewater is a common phenomenon [1-3]. For example, heavy metal ions such as $\mathrm{Ag}^{+}, \mathrm{Cr}^{6+}, \mathrm{Cu}^{2+}$, generated from rinsing of plated articles, often coexist with organic dyes such as methyl orange. Many studies have focused on single pollutant treatments, however, it is often difficult to treat mixed contaminants using photocatalysts designed for single pollutants [4]. Therefore, the design and preparation of photocatalysts which can be used to treat the mixed contaminants of heavy metal ions and organic compounds are very important for practical pollutant remediation.

Among the developed photocatalytic materials, layered double hydroxides (LDHs) can be considered ideal photocatalysts for the treatment of various types of pollutants due to multiple charge transport pathways, adjustable layer spacing, compositional flexibility, low manufacturing cost and 
absorption of visible light. Many studies have been reported on the photocatalytic degradation of heavy metal ions, organic compounds, and $\mathrm{CO}_{2}$ using LDHs as the photocatalyst [5-8]. The composition of LDHs with metal ions of variable valences (such as $\mathrm{Co}, \mathrm{Ni}, \mathrm{Fe}, \mathrm{Cr}$ ) could offer an effective pathway for electron-hole transportation and help to capture heavy metal ions in solution. For example, the Co(II) in CoAl-LDHs helps to capture Pd(II) species through an in situ redox reaction, resulting in the formation of Pd nanoclusters monodispersed on the surface of CoAl-LDHs [9]. It has also been shown that $\mathrm{Au} / \mathrm{Cr}$-substituted hydrotalcite could be an efficient heterogeneous catalyst for aerobic alcohol oxidation, owing to the formation of the $\mathrm{Cr}^{3+}-\mathrm{Cr}^{6+}$ redox cycle [10]. In addition, NiFe-LDHs have multiple electronic excitation pathways via metal-to-metal charge transfer through $\mathrm{Ni}^{2+}-\mathrm{O}-\mathrm{Fe}^{3+}, \mathrm{d}-\mathrm{d}$ transitions of $\mathrm{Ni}^{2+}$, and ligand-to-metal charge transfer through $\mathrm{O}-\mathrm{Ni}^{2+} / \mathrm{Fe}^{3+}[11]$.

The effective properties of photocatalytic materials could further be improved by the modification of metal ions or the formation of innovative compositions. For example, $\mathrm{Ag} @ \mathrm{Ag}_{3} \mathrm{PO}_{4} / \mathrm{g}-\mathrm{C}_{3} \mathrm{~N}_{4} / \mathrm{NiFe}-\mathrm{LDH}$ nanocomposites improved the photocatalytic ability for the reduction of $\mathrm{Cr}(\mathrm{VI})$ to $\mathrm{Cr}$ (III) [5]. Similarly, Ag nanoparticle-coated $\mathrm{Zn} / \mathrm{Ti}-\mathrm{LDH}$ composites showed higher photocatalytic activity for rhodamine $\mathrm{B}(\mathrm{RhB})$ and $\mathrm{NO}$, owing to the formation of Schottky barriers between LDH and $\mathrm{Ag}$ nanoparticles and the surface plasmon resonance effect of $\mathrm{Ag}$ nanoparticles [12]. Furthermore, NiFe-LDHs modified through ion doping with $\left[\mathrm{M}\left(\mathrm{C}_{2} \mathrm{O}_{4}\right)_{3}\right]^{3-}(\mathrm{M}=\mathrm{Cr}$ and $\mathrm{Rh})$ exhibited higher magnetic properties [13]. In another study, $\mathrm{Tb}^{3+}$-doped $\mathrm{CaAl}-\mathrm{LDH}$ showed an enhancement in fluorescence intensity [14], $\mathrm{H}_{2} \mathrm{SrTa}_{2} \mathrm{O}_{7}$ with difference photocatalytic activities toward $\mathrm{CO}$ and $\mathrm{H}_{2}$ evolution was obtained using various metals as cocatalysts ( $\mathrm{Ag}, \mathrm{Pd}, \mathrm{Au}$, and $\left.\mathrm{Cu}_{2} \mathrm{O}\right)$ [15], and the photocatalytic properties of ZnS were improved by modification with Ru nanoparticles [16]. Similar studies have shown that the formation of dual surface heterostructure by deposing $\mathrm{Au}$ and $\mathrm{CuO}$ on $\mathrm{Cu}_{2} \mathrm{O}$ cubes improved the photocatalytic activity of $\mathrm{Cu}_{2} \mathrm{O}$ due to the synergistic effect of $\mathrm{CuO} / \mathrm{Cu}_{2} \mathrm{O}$ and $\mathrm{Au} / \mathrm{Cu}_{2} \mathrm{O}$ [17]. However, in one study, the diffusion of $\mathrm{K}^{+}$ions from poly(heptazine imide) (PHIK) to a metal-organic framework (MOF) made PHIK more negatively charged and MOF more positively charged, which provided the strongest interaction between PHIK and MOF and resulted in superior photocatalytic activity through rhodamine B degradation [18]. It has also been shown that the formation of heterojunctions could increase photocatalytic properties, such as $\mathrm{Cu}_{2} \mathrm{~S} / \mathrm{ZnO}, \mathrm{Cu} \mathrm{O}_{2} \mathrm{O} / \mathrm{TiO}_{2}$, and $\mathrm{CuInS} / 2 / \mathrm{TiO}_{2}$ [19-21], and that the presence of $\mathrm{Na}_{2} \mathrm{~S}$ hole scavengers increased the photoreduction of $\mathrm{CO}_{2}$ to form $\left(\mathrm{HCOO}^{-}\right)$on $\mathrm{ZnS}$ [22]. Finally, due to the different Fermi levels between heavy metals and LDHs, heavy metals deposited on the surface of LDHs could act as electron traps to prevent electron-hole recombination $[5,9,10]$, which would improve the photocatalytic performance of LDHs.

According to the above discussion, LDHs could be used for the photocatalytic degradation of mixed wastewater. However, LDH powders exhibit the following drawbacks: low photocatalytic activity, formation of aggregates, and difficulties in subsequent separation processes. Using a two-dimensional structure with excellent carrier mobility as the substrate is an effective approach for enhancing the photocatalytic efficiency by preventing agglomeration and decreasing charge recombination [23,24]; besides, the formation of films on the substrate is beneficial for recovering the catalysts from the solution. Among those substrates, conductive cloth has the characteristics of good conductivity, flexibility, and low manufacturing cost. From this viewpoint, we used conductive cloth as the substrate and LDHs as the active sites for photocatalytic domains. Based on the photo-induced reduction and photocatalytic degradation of LDHs, LDH films were successfully used to treat the mixed wastewater containing heavy metal ions and organic compounds. The formation of heavy metals and LDHs on the surface of the conductive cloth led to an enhancement of the photocatalytic activity for organic pollutants degradation and, thereby, realized the photocatalytic treatment of mixed wastewater. 


\section{Materials and Methods}

\subsection{Materials}

$\mathrm{Al}\left(\mathrm{NO}_{3}\right)_{3} \cdot 9 \mathrm{H}_{2} \mathrm{O}, \quad \mathrm{Ni}\left(\mathrm{NO}_{3}\right)_{2} \cdot 6 \mathrm{H}_{2} \mathrm{O}, \mathrm{Fe}\left(\mathrm{NO}_{3}\right)_{3} \cdot 9 \mathrm{H}_{2} \mathrm{O}, \mathrm{AgNO}_{3}$, ferric ammonium citrate $\left(\left(\mathrm{NH}_{4}\right)_{3} \cdot\left[\mathrm{Fe}(\mathrm{Cit})_{2}\right]\right)$, urea, methyl orange, and ammonium fluoride $\left(\mathrm{NH}_{4} \mathrm{~F}\right)$ were purchased from Sinopharm Chemical Reagent Co. Ltd. (Shanghai, China) and used as received without further purification. The conductive cloth was purchased from Zhongyang shielding material production company, Guangzhou, China.

\subsection{Synthesis of LDH Films}

NiAl-LDH films were prepared using the method previously reported with some minor modifications [25]. The conductive cloth $(2 \mathrm{~cm} \times 6 \mathrm{~cm})$ was cleaned with a mixed solution of deionized water, ethanol, and acetone (volume ratio, 1:1:1) in an ultrasonic bath for $30 \mathrm{~min} . \mathrm{Ni}\left(\mathrm{NO}_{3}\right)_{2} \cdot 6 \mathrm{H}_{2} \mathrm{O}$ $\left(0.15 \mathrm{~mol} \cdot \mathrm{L}^{-1}\right), \mathrm{Al}\left(\mathrm{NO}_{3}\right)_{3} \cdot 9 \mathrm{H}_{2} \mathrm{O}\left(0.05 \mathrm{~mol} \cdot \mathrm{L}^{-1}\right), \mathrm{NH}_{4} \mathrm{~F}\left(0.2 \mathrm{~mol} \cdot \mathrm{L}^{-1}\right)$, and urea $\left(0.5 \mathrm{~mol} \cdot \mathrm{L}^{-1}\right)$ were dissolved in deionized water under magnetic stirring to form a clear solution at room temperature. The conductive cloth was vertically placed in the solution without stirring and heated at $110^{\circ} \mathrm{C}$ for $8 \mathrm{~h}$ to form a thin film on its bottom side, which was washed by deionized water. For NiFe-LDH films, $\mathrm{Fe}\left(\mathrm{NO}_{3}\right)_{3} \cdot 9 \mathrm{H}_{2} \mathrm{O}\left(0.05 \mathrm{~mol} \cdot \mathrm{L}^{-1}\right)$ was used instead of $\mathrm{Al}\left(\mathrm{NO}_{3}\right)_{3} \cdot 9 \mathrm{H}_{2} \mathrm{O}$. $\mathrm{LDH}$ powders were also prepared under the same experimental conditions as that of LDH films but without conductive cloth.

Fe-doped LDH films: LDH films were vertically placed in a $\left(\mathrm{NH}_{4}\right)_{3} \cdot\left[\mathrm{Fe}(\mathrm{Cit})_{2}\right]$ solution $\left(0.01 \mathrm{~mol} \cdot \mathrm{L}^{-1}\right)$ and heated at $75{ }^{\circ} \mathrm{C}$ for $12 \mathrm{~h}$ to form Fe-doped LDH films, which were cleaned with deionized water. For Fe-doped LDH powders, LDH powders were used instead of LDH films.

\subsection{Characterization}

X-ray powder diffraction (XRD) patterns were recorded using a D8 ADVANCE X-ray diffractometer (Karlsruhe, Germany) with $\mathrm{Cu} \mathrm{K}_{\alpha}$ radiation $(\lambda=0.15406 \mathrm{~nm})$. The scanning electron microscopy (SEM) images were recorded on a FEI-Sirion $200 \mathrm{~F}$ field emission scanning electron microscope (Hongkong, China). The transmission electron microscopy (TEM) images, high-resolution transmission electron microscopy (HRTEM) images, and the energy dispersive spectroscopy (EDS) spectra were taken with a FEI-Tecnai G2 field emission transmission electron microscope (Hongkong, China). The samples were obtained by peeling off $\mathrm{LDH}$ films from the substrate. Photocatalytic reactions were carried out using a $300 \mathrm{~W}$ Xe lamp as the light source and the light intensity in the visible region was about $85 \mathrm{~mW} \cdot \mathrm{cm}^{-2}$. The UV-Vis diffuse reflectance spectra were recorded by a UV-Vis spectrophotometer (UV-3900H, Hitachi, Tokyo, Japan). Fourier transform infrared (FTIR) spectra were recorded by a Thermo Nicolet 5700 (Waltham, MA, USA). The chemical state of LDHs was investigated by X-ray photoelectron spectroscopy (XPS) on a ESCALAB 250Xi photoelectron spectrometer (Waltham, MA, USA) with Al K (1486 Ev) as the excitation light source. The $\mathrm{N}_{2}$ adsorption/desorption tests were measured by Brunauer-Emmett-Teller (BET) measurements using a NOVA2200e surface area analyzer (Boynton Beach, FL, USA).

\subsection{Photocatalytic Property Measurement}

LDH films $(2 \mathrm{~cm} \times 6 \mathrm{~cm})$ were immersed in a mixed solutions of methyl orange $\left(20 \mathrm{mg} \cdot \mathrm{L}^{-1}\right)$ and $\mathrm{AgNO}_{3}\left(0,5,10,20\right.$, and $\left.30 \mathrm{mg} \cdot \mathrm{L}^{-1}\right)$ and kept in the dark for $30 \mathrm{~min}$ to ensure adsorption-desorption equilibrium. The $\mathrm{pH}$ value of the solution was about 6 . Samples were removed from the solution after various irradiation times and analyzed using a UV-Vis spectrophotometer at $464 \mathrm{~nm}$. All photocatalytic experiments were repeated three times. The weight of the photocatalyst was calculated from the formula $m=m_{1}-m_{0}$, where $m_{0}$ and $m_{1}$ represent the weight of the substrate before and after LDH growth, respectively. The LDHs grown on conductive cloth were about 6.6, 6.9, 6.5, and $6.7 \mathrm{mg}$ for NiAl-LDH films, NiFe-LDH films, Fe-doped NiAl-LDH films, and Fe-doped NiFe-LDH films, 
respectively. To test the photocatalytic performance of LDH powders, LDH powders (15 mg) were used instead of LDH films.

\section{Results and Discussion}

XRD analysis was performed to confirm the crystal structure and phase (Figure S1). Both the structure of NiAl-LDH films and NiFe-LDH films matched well to the typical LDH lamellar structure (JCPDS File No. 48-0594 and 51-0463). According to the (003), (006), and (009) reflections, the basal spacing values were $0.756 \mathrm{~nm}$ (NiAl-LDHs) and $0.764 \mathrm{~nm}$ (NiFe-LDHs), which coincide well with the values for $\mathrm{CO}_{3}{ }^{2-}$-intercalated LDH materials [26]. The Fe-doped LDH films displayed a phase of lamellar structures with a slightly lower degree of crystallinity and basal spacing $(0.755$ and $0.762 \mathrm{~nm}$ for Fe-doped NiAl-LDH films and Fe-doped NiFe-LDH films, respectively) which was lower than that of Fe complex-intercalated LDHs $(1.214 \mathrm{~nm})$ [27]. This suggests that the interlayer ion of LDHs was $\mathrm{CO}_{3}{ }^{2-}$ and that no Fe complex intercalated in the interlayer. According to the (003) crystal plane spacing, grain size and stacking numbers of LDHs in the direction of the $c$ axis were calculated using the Scherrer formula. The grain size for NiFe-LDH films and NiAl-LDH films were 43.2 and $33.9 \mathrm{~nm}$, respectively, whereas the stacking numbers for NiFe-LDH films and NiAl-LDH films were 57 and 45 , respectively.

The chemical state of Fe ions in the LDH films was investigated by XPS spectra. The peaks at 726.28 and $712.78 \mathrm{eV}$ are attributed to the $2 \mathrm{p} 1 / 2$ and 2p3/2 spin states of Fe(III) for LDH lamellar structure [28-32] as seen in Figure 1a. After Fe ion doping, the positions of Fe 2p3/2 were basically the same (within the experimental uncertainty [33]), while the peaks for Fe 2p1/2 in both LDH films showed a negative shift of $\sim 0.4$ and $0.6 \mathrm{eV}$, as shown in Figure 1b,c. The mole ratio of Fe/Ni for Fe-doped NiFe-LDH films and Fe-doped NiAl-LDH films were 0.58:1 and 0.38:1, respectively. The increase in the mole ratio of $\mathrm{Fe} / \mathrm{Ni}$ after doping indicates successful doping of $\mathrm{Fe}$ ions. No peaks for Fe complexes (725.0 and $711.5 \mathrm{eV}$ ) were observed, confirming that no Fe complex intercalated into the LDH films [28].

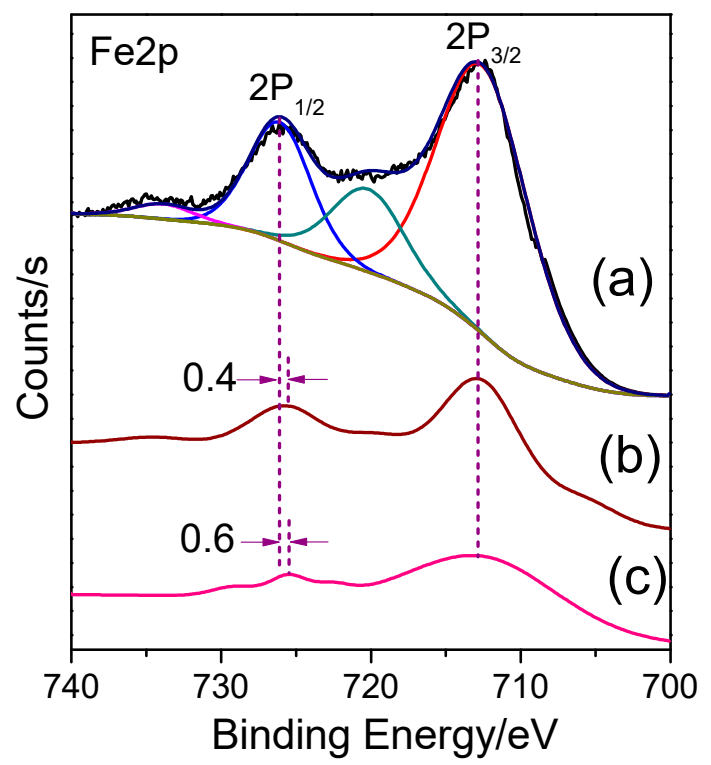

Figure 1. The high-resolution Fe 2p XPS spectra of (a) NiFe-LDH films, (b) Fe-doped NiFe-LDH films, and (c) Fe-doped NiAl-LDH films.

As seen in Figure 2, FTIR spectra of all LDH films provide evidence for the presence of intercalated $\mathrm{CO}_{3}{ }^{2-}$ and interlayered water. After $\mathrm{Fe}(\mathrm{III})$ doping, the peak position of $\mathrm{CO}_{3}{ }^{2-}$ moved toward high frequency (around $1388 \mathrm{~cm}^{-1}$ ) due to the change in charge density by doping $\mathrm{Fe}(\mathrm{III})$ into the LDH films [34]. No vibration peak $\left(1290 \mathrm{~cm}^{-1}\right)$ for an Fe complex appeared. 


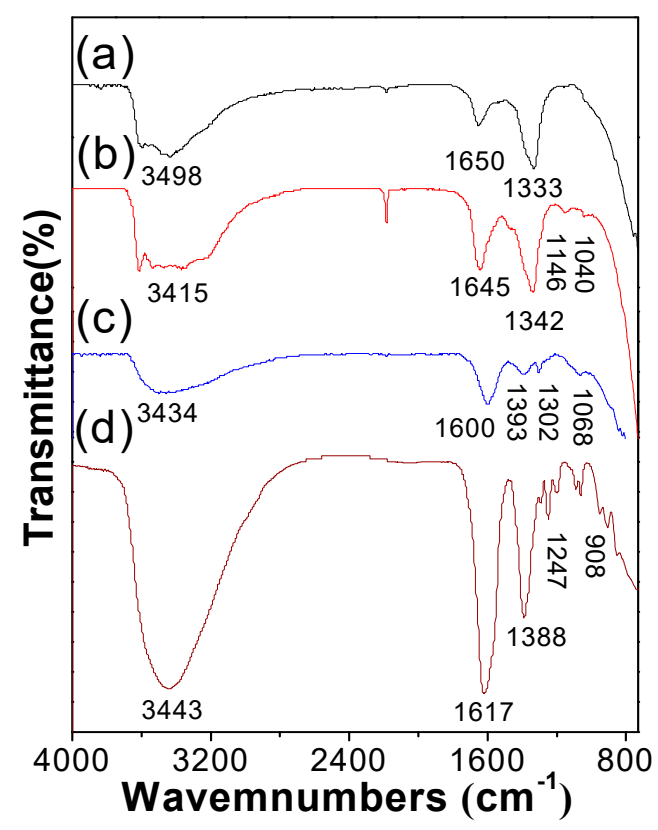

Figure 2. FTIR spectra of (a) NiFe-LDH films, (b) NiAl-LDH films, (c) Fe-doped NiAl-LDH films, and (d) Fe-doped NiFe-LDH films.

Figure 3 shows morphology images of the LDH films obtained using SEM analysis and suggests typical sheet-like structures uniformly distributed on the surface of the substrate, thus effectively solving the problem of powder agglomeration. Figure 3a shows NiAl-LDH sheets intersecting and aligned vertically on the conductive cloth under the orienting function of $\mathrm{NH}_{4} \mathrm{~F}$ [10]. $\mathrm{NiFe}-\mathrm{LDH}$ films also exhibited a similar sheet-like morphology, as seen in Figure 3b, but the sheets were larger and more loosely distributed. The composition of the LDHs affected the sheet thickness, which was consistent with the results from XRD analysis. After Fe ion doping, NiAl-LDH and NiFe-LDH sheets displayed a lamellar structure of similar size. TEM investigation of LDH films revealed the almost transparent, thin, layered morphology of the sheets, as shown in Figure 4. All HRTEM images exhibited clear lattice fringes with a d-spacing value of $0.2593 \mathrm{~nm}$ corresponding to (012) reflection from the LDHs.

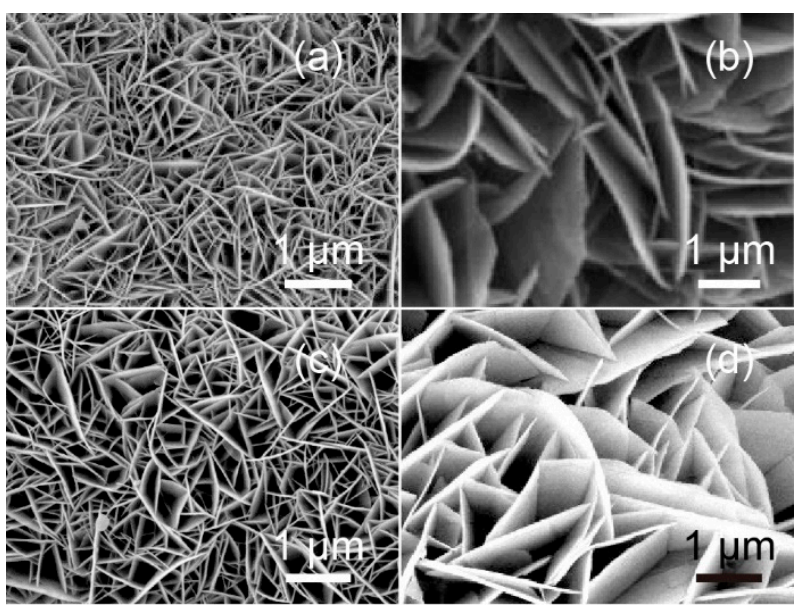

Figure 3. SEM images of (a) NiAl-LDH films, (b) NiFe-LDH films, (c) Fe-doped NiAl-LDH films, and (d) Fe-doped NiFe-LDH films. 


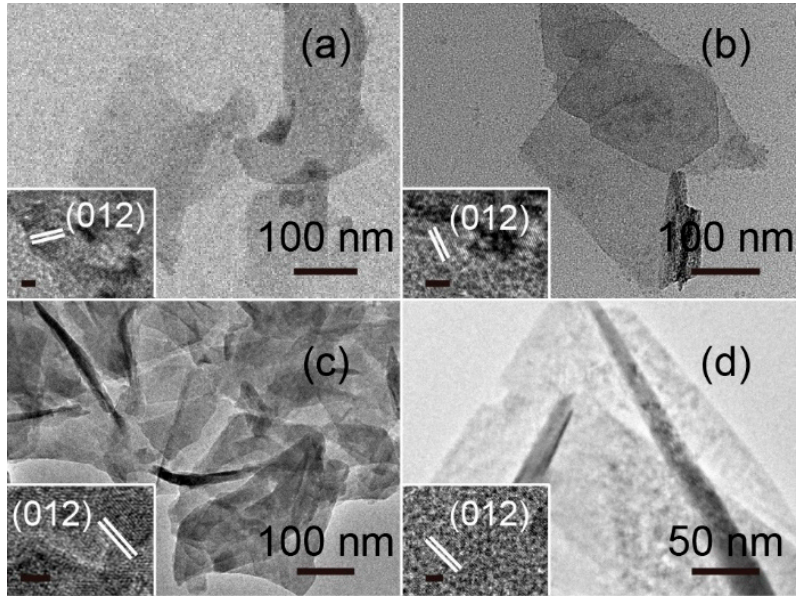

Figure 4. TEM images of (a) NiAl-LDH films, (b) NiFe-LDH films, (c) Fe-doped NiAl-LDH films, and (d) Fe-doped NiFe-LDH films. Insets are corresponding HRTEMs, scale bar: $2 \mathrm{~nm}$.

The photocatalytic activity in methyl orange degradation under visible-light irradiation was evaluated, as shown in Figure 5a. All LDH films showed a weak adsorption effect after treatment in a dark place for $30 \mathrm{~min}$. Figure $5 \mathrm{~b}$ illustrates the blank experiment-in the absence of catalysts but under irradiation, showed that a small quantity of methyl orange was degraded Figure $5 b$. No obvious photosensitive degradation of methyl orange was observed. The degradation of methyl orange mainly depends on photocatalytic activity, which tends to increase with increasing irradiation time. In general, the photocatalytic activity depends on the amount of catalyst. Within a certain range, the use of more photocatalyst provides higher photocatalytic activity [35]. In our experiments, the degradation of methyl orange per milligram of LDHs was used to describe the photocatalytic activity. Under $120 \mathrm{~min}$ illumination, the degradation of methyl orange for NiAl-LDH and NiFe-LDH films was $9.1 \% \cdot \mathrm{mg}^{-1}$ and $8.4 \% \cdot \mathrm{mg}^{-1}$, respectively. When Fe-doped LDH films were used as a photocatalyst, the degradation of methyl orange decreased.
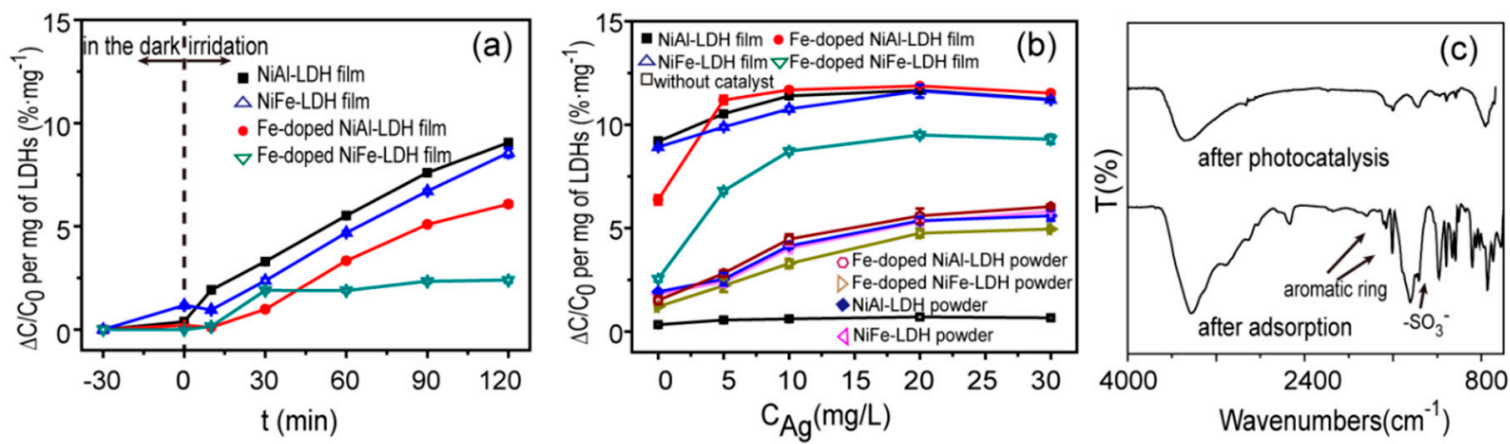

Figure 5. (a) Photocatalytic activity of methyl orange for LDH films without Ag ions. (b) Effect of Ag ion concentration on degradation of methyl orange under 120 min illumination. $\mathrm{C}_{0}$ : the equilibrium concentration of methyl orange before irradiation, $\Delta \mathrm{C}$ : the change in the concentration of methyl orange after irradiation. (c) FTIR spectra of NiAl-LDH films after photocatalytic experiments and adsorption experiments.

The $\mathrm{Fe}(\mathrm{III})$ ionic radius (64.5 pm) is larger than $\mathrm{Al}(\mathrm{III})$ ionic radius (53.5 pm); hence, the replacement of $\mathrm{Al}(\mathrm{III})$ by Fe(III) could increase the distance between metal ions in the layer and reduce the charge density. This is unfavorable to electron-hole transfer throughout the layered framework, and thereby leads to a low level of photocatalytic activity as shown in Figure 6a [5,7]. Therefore, NiAl-LDH films showed better photocatalytic activity compared to NiFe-LDH films. The Figure $6 \mathrm{~b}$ pathway 3 shows that after Fe doping, Fe(III) ions act as traps for photogenerated electron-hole pairs and accelerate 
electron-hole pair recombination [36-38], thus decreasing the photocatalytic degradation of methyl orange by Fe-doped LDH films.

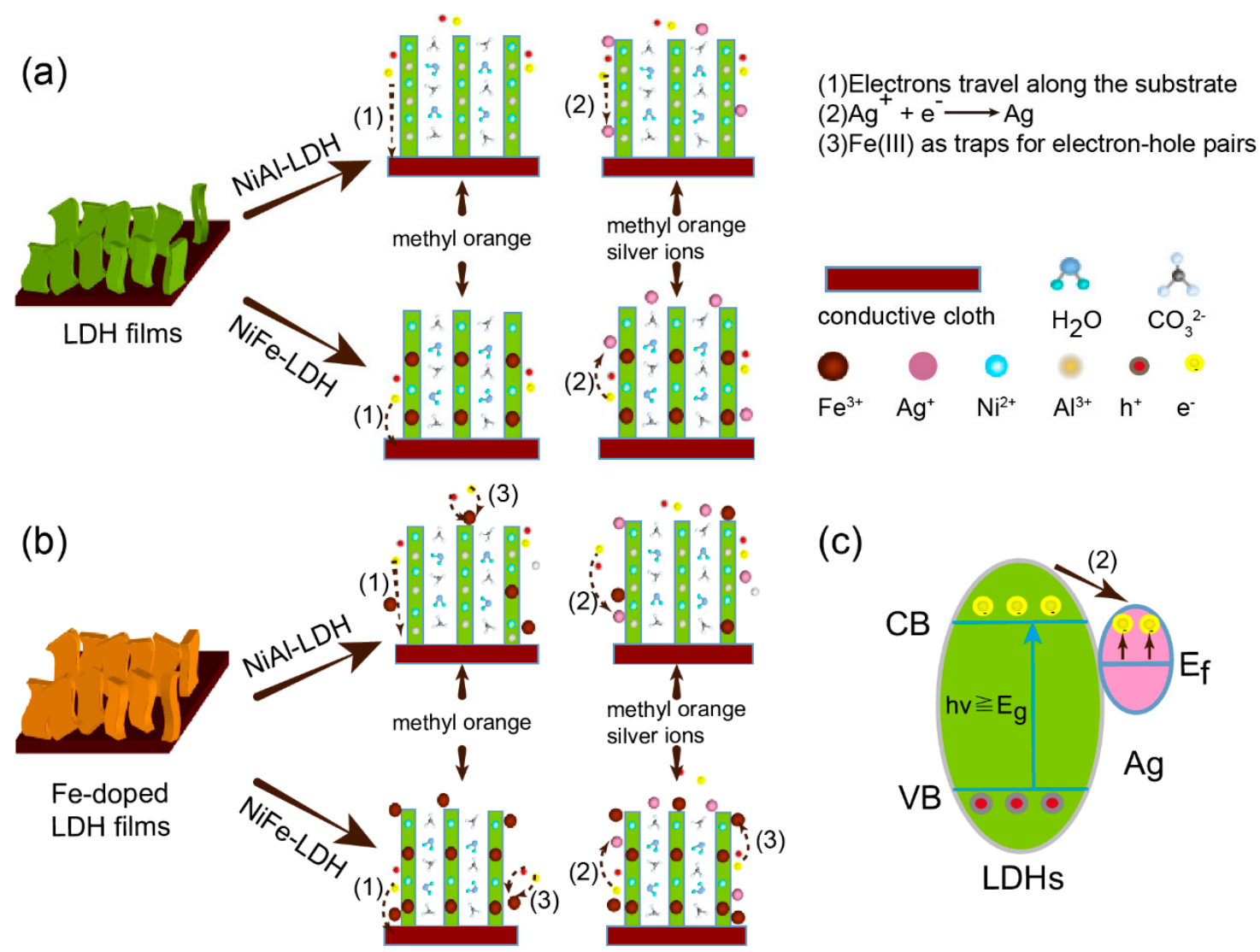

Figure 6. Schematic diagram of possible electron transport in (a) LDH films and (b) Fe-doped LDH films in degradation of methyl orange or a mixed solution of methyl orange and Ag ions. (c) Possible electron transport between LDHs and Ag nanoparticles.

The photocatalytic activity of LDH films was studied in mixed wastewater containing Ag ions and methyl orange. The degradation of methyl orange was gradually accelerated when the concentration of $\mathrm{Ag}$ ions increased from 0 to $20 \mathrm{mg} \cdot \mathrm{L}^{-1}$, as seen in Figure $5 \mathrm{~b}$. Fe-doped NiAl-LDH films exhibited the best photocatalytic activity with $20 \mathrm{mg} \cdot \mathrm{L}^{-1} \mathrm{Ag}$ ion concentration and $11.92 \% \cdot \mathrm{mg}^{-1}$ degradation rate of methyl orange, which is higher than reported values (degradation of methyl orange for xanthan gum $/ \mathrm{TiO}_{2}$ [35], $\mathrm{MnO}_{2}-\mathrm{M}$ [39], and $\mathrm{WO}_{3} / \mathrm{g}-\mathrm{C}_{3} \mathrm{~N}_{4}$ [40] were $2.3 \%, 9.5 \%$, and $4.84 \% \cdot \mathrm{mg}^{-1}$, respectively). When the concentration of Ag ions in solution was further increased from $20 \mathrm{mg} \cdot \mathrm{L}^{-1}$, the degradation of methyl orange decreased slightly due to the light shielding effect of Ag ions adsorbed on the surface of LDHs.

In the presence of Ag ions, the degradation of methyl orange by LDH films was higher as seen in Figure 5b. Figure 6, pathway 2 shows Ag nanoparticles were reduced from the solution and deposited on the surface of the LDH films, which received electrons and promoted the separation of photogenic electron-hole pairs [41], thus improving the photocatalytic activity of LDH films. That is, the electron traps of Ag nanoparticles prevented the recombination of electron-hole pairs on Fe(III) ions. The capture of electrons and holes by Ag nanoparticles and Fe(III) ions promoted the separation of electron-hole pairs. As a result, when the concentration of Ag ions increased from 0 to $20 \mathrm{mg} \cdot \mathrm{L}^{-1}$, there was a large increase in the degradation of methyl orange by Fe-doped LDH films, as shown in Figure $5 b$.

For comparison, corresponding LDH powders were also prepared. All of the LDH powders showed similar sheet-like morphology and lamellar structure to that of LDH films, as shown in Figures 
S2 and S3. However, as seen in Figure 5b, the photocatalytic degradation of methyl orange by LDH powders was lower than that of LDH films, which confirms that the conductive cloth could facilitate the transportation of photogenerated charges shown in Figure 6a,b, pathway 1 [23]. However, this comparison is qualitative and we will further study the kinetics of excitons and free carriers in LDH films, for example, the charge transfer dynamics, to obtain the quantitative properties of LDH films [42-44]. In addition, LDH films could be easily separated from the solution, providing a simple method for the recovery of the catalyst.

We also used FTIR spectra to investigate LDH films after photocatalytic degradation and adsorption experiments, as shown in Figure 5c. After photocatalytic degradation of methyl orange, the peak intensity of $\mathrm{CO}_{3}{ }^{2-}$ decreased and no obvious peaks for methyl orange were observed. While after adsorption experiments, some peaks for methyl orange were observed. The differences between photocatalytic degradation and adsorption experiments confirm that the degradation of methyl orange in the presence of LDH films was not through adsorption.

The LDH films after the photocatalytic reaction were examined by TEM and EDS. No noticeable change was observed in the morphology of LDH films before and after the photocatalytic reaction. LDH films exhibited good stability for the degradation of methyl orange. As shown in Figure 7, the LDH sheets were transparent to the electron beam, suggesting that they were very thin. The insets in Figure 7a-c show that after the photocatalytic reaction, the HRTEM images taken from one sheet can be indexed to the $\left(\begin{array}{lll}0 & 0 & 10\end{array}\right)$ plane, which matches well with the reported values of the LDH structure. Figure 7c shows that in the presence of Ag ions, some Ag nanoparticles were observed on the surface of LDH sheets. The lattice spacing of $0.2083 \mathrm{~nm}$ can be indexed to the (200) plane of Ag nanoparticles. EDS spectra also confirmed the formation of Ag after photocatalytic reaction, as seen in Figure S5.
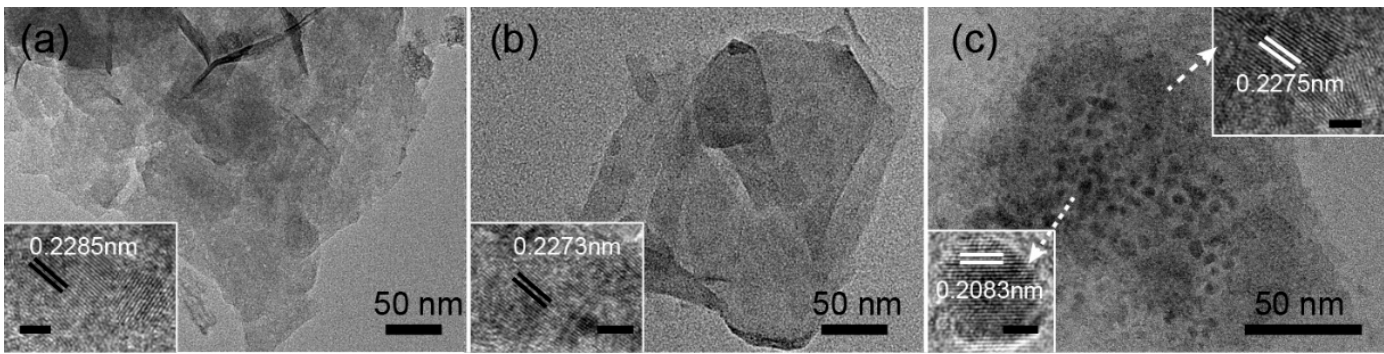

Figure 7. TEM images after photocatalytic reaction (a) NiAl-LDH films, (b) Fe-doped NiAl-LDH films, and (c) Fe-doped NiAl-LDH films in the presence of $5 \mathrm{mg} \cdot \mathrm{L}^{-1} \mathrm{Ag}$ ions. Insets are corresponding HRTEM images. Scales in insets are $2 \mathrm{~nm}$.

\section{Conclusions}

LDH films and Fe-doped LDH films with different compositions (Ni, Al, and Fe) on the surface of conductive cloth were successfully prepared and applied for photocatalytic degradation of methyl orange in mixed wastewater. All LDH films showed layered structures and were distributed uniformly on the surface of the substrate. They exhibited high photocatalytic performance and could be easily separated from the solution, providing a simple method for the recovery of the catalyst. Benefiting from the electron trap of Ag nanoparticles, the photocatalytic activity of LDH films on methyl orange was improved, and the Fe-doped NiAl-LDH films presented the best visible-light photocatalytic performance. Our study indicates that LDH films can be used in the treatment of mixed wastewater and have broad application prospects for environmental remediation and purification processes. In order to better realize the application of LDH films in wastewater treatment, further research is needed, including 1) to explore different conductive substrates with excellent carrier mobility which could influence the photocatalytic performance of LDHs; and 2) to explore the reducing capacity of LDH films to other heavy metal ions with different Fermi levels in order to prevent hole-electron recombination, thereby enhancing photocatalytic activity. Based on such research, the factors affecting the photocatalytic performance of LDH films can be better understood. By adjusting the structure 
and composition of LDHs, different types of mixed wastewater containing heavy metal ions and organic compounds can be selectively treated. We envision that our findings will help in further development of new, improved, and more effective LDH films with enhanced photocatalytic activity for the treatment of mixed wastewater.

Supplementary Materials: The following are available online at http://www.mdpi.com/2079-4991/9/6/807/s1, Table S1: XPS Peak positions for $\mathrm{Fe}^{3+}$ obtained from $\mathrm{LDH}$ films and Fe-doped LDH films. Figure S1: XRD patterns. (a) NiAl-LDH films, (b) NiFe-LDH films, (c) Fe-doped NiAl-LDH films, and (d) Fe-doped NiFe-LDH films. Figure S2: SEM images. (a) NiAl-LDH powders, (b) NiFe-LDH powders, (c) Fe-doped NiAl-LDH powders, and (d) Fe-doped NiFe-LDH powders. Figure S3: XRD patterns. (a) NiAl-LDH powders, (b) Fe-doped NiAl-LDH powders, (c) NiFe-LDH powders, and (d) Fe-doped NiFe-LDH powders. Figure S4: EDS elements mapping for Fe-doped NiAl-LDH films after the photocatalytic degradation in the presence of methyl orange $\left(20 \mathrm{mg} \cdot \mathrm{L}^{-1}\right)$ and Ag ions $\left(5 \mathrm{mg} \cdot \mathrm{L}^{-1}\right)$. (a) Area without Ag particles, (b) area with Ag particles. Figure S5: EDS spectra for Fe-doped $\mathrm{NiAl}-\mathrm{LDH}$ films after photocatalytic reaction in the presence of $5 \mathrm{mg} \cdot \mathrm{L}^{-1} \mathrm{Ag}$ ions. (a) Area with Ag nanoparticles, (b) area without Ag nanoparticles in Figure 7c. Figure S6: $\mathrm{N}_{2}$ adsorption/desorption isotherms of (a) NiAl-LDH powders and Fe-doped NiAl-LDH powders, (b) NiFe-LDH powders and Fe-doped NiFe-LDH powders.

Author Contributions: Conceptualization, Z.W., W.W. and J.L.; Data curation, Z.W., P.F. and W.W.; Funding acquisition, W.W.; Methodology, Z.W. and P.F.; Project administration, W.W. and B.L.; Supervision, W.W.; Writing-Original Draft, Z.W., P.F. and W.W.; Writing-Review \& Editing, P.K., W.W., B.L. and J.L.

Funding: This research was funded by Natural Science Foundation of Shandong Province (grant numbers ZR2015BM022).

Acknowledgments: Thanks Huan Yu for the useful discussion of the experiments.

Conflicts of Interest: The authors declare no conflict of interest.

\section{References}

1. Chen, S.; Huang, Y.; Han, X.; Wu, Z.; Li, C.; Wang, J.; Deng, Q.; Zeng, Z.; Deng, S. Simultaneous and efficient removal of $\mathrm{Cr}(\mathrm{VI})$ and methyl orange on LDHs decorated porous carbons. Chem. Eng. J. 2018, 352, 306-315. [CrossRef]

2. Yang, Y.; Wang, G.; Deng, Q.; Ng, D.H.L.; Zhao, H. Microwave-assisted fabrication of nanoparticulate $\mathrm{TiO}_{2}$ microspheres for synergistic photocatalytic removal of $\mathrm{Cr}(\mathrm{VI})$ and methyl orange. ACS Appl. Mater. Interfaces 2014, 6, 3008-3015. [CrossRef]

3. Li, X.; Liu, Y.; Zhang, C.; Wen, T.; Zhuang, L.; Wang, X.; Song, G.; Chen, D.; Ai, Y.; Hayat, T.; et al. Porous $\mathrm{Fe}_{2} \mathrm{O}_{3}$ microcubes derived from metal organic frameworks for efficient elimination of organic pollutants and heavy metal ions. Chem. Eng. J. 2018, 336, 241-252. [CrossRef]

4. Zhao, G.; Sun, Y.; Zhao, Y.; Wen, T.; Wang, X.; Chen, Z.; Sheng, G.; Chen, C.; Wang, X. Enhanced photocatalytic simultaneous removals of $\mathrm{Cr}(\mathrm{VI})$ and bisphenol A over $\mathrm{Co}(\mathrm{II})$-modified $\mathrm{TiO}_{2}$. Langmuir 2019, 35, $276-283$. [CrossRef] [PubMed]

5. Nayak, S.; Parida, K.M. Dynamics of charge-transfer behavior in a plasmon-induced quasi-type-II p-n/n-n dual heterojunction in $\mathrm{Ag} @ \mathrm{Ag}_{3} \mathrm{PO}_{4 / g}-\mathrm{C}_{3} \mathrm{~N}_{4} / \mathrm{NiFe} \mathrm{LDH}$ nanocomposites for photocatalytic $\mathrm{Cr}(\mathrm{VI})$ reduction and phenol oxidation. ACS Omega 2018, 3, 7324-7343. [CrossRef]

6. Zhang, Q.; Li, S.; Jing, R.; Wu, M.; Zhao, S.; Liu, A.; Liu, Y.; Meng, Z. Superlattice assembly of two dimensional CoFe-LDHs nanosheets and titania nanosheets nanohybrids for high visible light photocatalytic activity. Mater. Lett. 2019, 236, 374-377. [CrossRef]

7. Salehi, G.; Abazari, R.; Mahjoub, A.R. Visible-light-induced graphitic- $\mathrm{C}_{3} \mathrm{~N}_{4}$ @nickel-aluminum layered double hydroxide nanocomposites with enhanced photocatalytic activity for removal of dyes in water. Inorg. Chem. 2018, 57, 8681-8691. [CrossRef]

8. Tonda, S.; Kumar, S.; Bhardwaj, M.; Yadav, P.; Ogale, S. g- $\mathrm{C}_{3} \mathrm{~N}_{4} / \mathrm{NiAl-LDH} 2 \mathrm{D} / 2 \mathrm{D}$ hybrid heterojunction for high-performance photocatalytic reduction of $\mathrm{CO}_{2}$ into renewable fuels. ACS Appl. Mater. Interfaces 2018, 10, 2667-2678. [CrossRef]

9. Li, P.; Huang, P.; Wei, F.; Sun, Y.; Cao, C.; Song, W. Monodispersed Pd clusters generated in situ by their own reductive support for high activity and stability in cross-coupling reactions. J. Mater. Chem. A 2014, 2, 12739-12745. [CrossRef] 
10. Liu, P.; Degirmenci, V.; Hensen, E. Unraveling the synergy between gold nanoparticles and chromium-hydrotalcites in aerobic oxidation of alcohols. J. Catal. 2014, 313, 80-91. [CrossRef]

11. Mohapatra, L.; Parida, K. A review on the recent progress, challenges and perspective of layered double hydroxides as promising photocatalysts. J. Mater. Chem. A 2016, 4, 10744-10766. [CrossRef]

12. Zhu, Y.; Zhu, R.; Zhu, G.; Wang, M.; Chen, Y.; Zhu, J.; Xi, Y.; He, H. Plasmonic Ag coated Zn/Ti-LDH with excellent photocatalytic activity. Appl. Surf. Sci. 2018, 433, 458-467. [CrossRef]

13. Coronado, E.; Martí-Gastaldo, C.; Navarro-Moratalla, E.; Ribera, A. Intercalation of $\left[\mathrm{M}(\mathrm{ox})_{3}\right]^{3-}(\mathrm{M}=\mathrm{Cr}, \mathrm{Rh})$ complexes into Ni ${ }^{\mathrm{II}} \mathrm{Fe}^{\mathrm{III}}$-LDH. Appl. Clay Sci. 2010, 48, 228-234. [CrossRef]

14. Chen, Y.; Zhang, J.; Wang, X.; Wang, L. Fluorescence enhancement of $\mathrm{Tb}^{3+}$-doped CaAl-LDH by cytosine. J. Lumin. 2018, 204, 42-50. [CrossRef]

15. Chen, W.; Wang, Y.; Shangguan, W. Metal (oxide) modified ( $\mathrm{M} \frac{1}{4} \mathrm{Pd}, \mathrm{Ag}$, $\mathrm{Au}$ and $\mathrm{Cu}$ ) $\mathrm{H}_{2} \mathrm{SrTa}_{2} \mathrm{O}_{7}$ for photocatalytic $\mathrm{CO}_{2}$ reduction with $\mathrm{H}_{2} \mathrm{O}$ : the effect of cocatalysts on promoting activity toward $\mathrm{CO}$ and $\mathrm{H}_{2}$ evolution. Int. J. Hydrogen Energ. 2019, 44, 4123-4132. [CrossRef]

16. Baran, T.; Wojtyla, S.; Dibenedetto, A.; Aresta, M.; Macyk, W. Zinc sulfide functionalized with ruthenium nanoparticles for photocatalytic reduction of $\mathrm{CO}_{2}$. Appl. Catal. B-Enviro. 2015, 178, 170-176. [CrossRef]

17. Jiang, D.; Zhang, Y.; $\mathrm{Li}, \mathrm{X}$. Synergistic effects of $\mathrm{CuO}$ and $\mathrm{Au}$ nanodomains on $\mathrm{Cu}_{2} \mathrm{O}$ cubes for improving photocatalytic activity and stability. Chinese J. Catal. 2019, 40, 105-113. [CrossRef]

18. Rodríguez, N.A.; Savateev, A.; Grela, M.A.; Dontsova, D. Facile Synthesis of Potassium Poly(heptazine imide) (PHIK)/Ti-Based Metal-Organic Framework (MIL-125-NH $\mathrm{N}_{2}$ Composites for Photocatalytic Applications. ACS Appl. Mater. Interfaces 2017, 9, 22941-22949. [CrossRef]

19. Han, D.; Li, B.; Yang, S.; Wang, X.; Gao, W.; Si, Z.; Zuo, Q.; Li, Y.; Li, Y.; Duan, Q.; et al. Engineering Charge Transfer Characteristics in Hierarchical Cu 2 S QDs @ ZnO Nanoneedles with p-n Heterojunctions: Towards Highly Efficient and Recyclable Photocatalysts. Nanomaterials 2019, 9, 16. [CrossRef] [PubMed]

20. Aguirre, M.E.; Zhou, R.; Eugene, A.J.; Guzman, M.I.; Grela, M.A. $\mathrm{Cu}_{2} \mathrm{O} / \mathrm{TiO}_{2}$ heterostructures for $\mathrm{CO}_{2}$ reduction through a direct Z-scheme: Protecting $\mathrm{Cu}_{2} \mathrm{O}$ from photocorrosion. Appl. Catal. B-Enviro. 2017, 217, 485-493. [CrossRef]

21. Xu, F.; Zhang, J.; Zhu, B.; Yu, J.; Xu, J. CuInS 2 sensitized $\mathrm{TiO}_{2}$ hybrid nanofibers for improved photocatalytic $\mathrm{CO}_{2}$ reduction. Appl. Catal. B-Enviro. 2018, 230, 194-202. [CrossRef]

22. Zhou, R.; Guzman, M.I. $\mathrm{CO}_{2}$ Reduction under Periodic Illumination of ZnS. J. Phys. Chem. C 2014, 118, 11649-11656. [CrossRef]

23. Lan, M.; Fan, G.; Yang, L.; Li, F. Significantly enhanced visible-light-induced photocatalytic performance of hybrid Zn-Cr layered double hydroxide/graphene nanocomposite and the mechanism study. Ind. Eng. Chem. Res. 2014, 53, 12943-12952. [CrossRef]

24. Chowdhury, P.R.; Bhattacharyya, K.G. Ni/Co/Ti layered double hydroxide for highly efficient photocatalytic degradation of Rhodamine B and Acid Red G: A comparative study. Photochem. Photobiol. Sci. 2017, 16, 835-839. [CrossRef] [PubMed]

25. Wu, X.; Ci, C.; Du, Y.; Liu, X.; Li, X.; Xie, X. Facile synthesis of NiAl-LDHs with tunable establishment of acid-base activity sites. Mater. Chem. Phys. 2018, 211, 72-78. [CrossRef]

26. Jiang, D.B.; Jing, C.; Yuan, Y.; Feng, L.; Liu, X.; Dong, F.; Dong, B.; Zhang, Y.X. 2D-2D growth of NiFe LDH nanoflakes on montmorillonite for cationic and anionic dye adsorption performance. J. Colloid. Interf. Sci. 2019, 540, 398-409. [CrossRef] [PubMed]

27. Parida, K.; Sahoo, M.; Singha, S. A novel approach towards solvent-free epoxidation of cyclohexene by Ti(IV)-Schiff base complex-intercalated LDH using $\mathrm{H}_{2} \mathrm{O}_{2}$ as oxidant. J. Catal. 2010, 276, 161-169. [CrossRef]

28. Huang, Z.; Wu, P.; Zhang, X.; Wang, X.; Zhu, N.; Wu, J.; Li, P. Intercalation of Fe(III) complexes into layered double hydroxides: Synthesis and structural preservation. Appl. Clay Sci. 2012, 65-66, 87-94. [CrossRef]

29. Rajeshkhanna, G.; Singh, T.I.; Kim, N.H.; Lee, J.H. Remarkable bifunctional oxygen and hydrogen evolution electrocatalytic activities with trace-Level Fe doping in $\mathrm{Ni}$ - and Co-layered double hydroxides for overall water-splitting. ACS Appl. Mater. Interfaces 2018, 10, 42453-42468. [CrossRef]

30. Zhou, T.; Cao, Z.; Zhang, P.; Ma, H.; Gao, Z.; Wang, H.; Lu, Y.; He, J.; Zhao, Y. Transition metal ions regulated oxygen evolution reaction performance of Ni-based hydroxides hierarchical nanoarrays. Sci. Rep. 2017, 7, 46154. [CrossRef] 
31. Zhu, Y.; Zhao, X.; Li, J.; Zhang, H.; Chen, S.; Han, W.; Yang, D. Surface modification of hematite photoanode by NiFe layered double hydroxide for boosting photoelectrocatalytic water oxidation. J. Alloys Compd. 2018, 764, 341-346. [CrossRef]

32. Youn, D.H.; Park, Y.B.; Kim, J.Y.; Magesh, G.; Jang, Y.J.; Lee, J.S. One-pot synthesis of NiFe layered double hydroxide/reduced graphene oxide composite as an efficient electrocatalyst for electrochemical and photoelectrochemical water oxidation. J. Power Sources 2015, 294, 437-443. [CrossRef]

33. Bajnóczi, E.G.; Balázs, N.; Mogyorósi, K.; Srankó, D.F.; Pap, Z.; Ambrus, Z.; Canton, S.; Norén, K.; Kuzmann, E.; Vértes, A.; et al. The influence of the local structure of $\mathrm{Fe}(\mathrm{III})$ on the photocatalytic activity of doped $\mathrm{TiO}_{2}$ photocatalysts-An EXAFS, XPS and Mósbauer spectroscopic study. Appl. Catal. B-Enviro. 2011, 103, 232-239. [CrossRef]

34. Ambrogi, V.; Perioli, L.; Nocchetti, M.; Latterini, L.; Pagano, C.; Massetti, E.; Rossi, C. Immobilization of kojic acid in ZnAl-hydrotalcite like compounds. J. Phys. Chem. Solids. 2012, 73, 94-98. [CrossRef]

35. Inamuddin. Xanthan gum/titanium dioxide nanocomposite for photocatalytic degradation of methyl orange dye. Int. J. Biol. Macromol. 2019, 121, 1046-1053. [CrossRef]

36. Reszczynska, J.; Grzyb, T.; Sobczak, J.W.; Lisowski, W.; Gazda, M.; Ohtani, B.; Zaleska, A. Visible light activity of rare earth metal doped $\left(\mathrm{Er}^{3+}, \mathrm{Yb}^{3+}\right.$ or $\left.\mathrm{Er}^{3+} / \mathrm{Yb}^{3+}\right)$ titania photocatalysts. Appl. Catal. B-Enviro. 2015, 163, 40-49. [CrossRef]

37. Boppella, R.; Choi, C.; Moon, J.; Kim, D.H. Spatial charge separation on strongly coupled 2D-hybrid of $\mathrm{rGO} / \mathrm{La}_{2} \mathrm{Ti}_{2} \mathrm{O}_{7 /} \mathrm{NiFe}-\mathrm{LDH}$ heterostructures for highly efficient noble metal free photocatalytic hydrogen generation. Appl. Catal. B-Enviro. 2018, 239, 178-186. [CrossRef]

38. Ambrus, Z.; Balázs, N.; Alapi, T.; Wittmann, G.; Sipos, P.; Dombi, A.; Mogyorósi, K. Synthesis, structure and photocatalytic properties of $\mathrm{Fe}(\mathrm{III})$-doped $\mathrm{TiO}_{2}$ prepared from $\mathrm{TiCl}_{3}$. Appl. Catal. B-Enviro. 2008, 81, 27-37. [CrossRef]

39. Zhang, Y.; Zheng, T.X.; Hu, Y.B.; Guo, X.L.; Peng, H.H.; Zhang, Y.X.; Feng, L.; Zheng, H.L. Delta manganese dioxide nanosheets decorated magnesium wire for the degradation of methyl orange. J. Colloid Interf. Sci. 2017, 490, 226-232. [CrossRef]

40. Chen, G.; Bian, S.; Guo, C.Y.; Wu, X. Insight into the Z-scheme heterostructure $\mathrm{WO}_{3} / \mathrm{g}-\mathrm{C}_{3} \mathrm{~N}_{4}$ for enhanced photocatalytic degradation of methyl orange. Mater. Lett. 2019, 236, 596-599. [CrossRef]

41. Lva, J.; Zhu, Q.; Zeng, Z.; Zhang, M.; Yang, J.; Zhao, M.; Wang, W.; Cheng, Y.; He, G.; Sun, Z. Enhanced photocurrent and photocatalytic properties of porous $\mathrm{ZnO}$ thin film by Ag nanoparticles. J. Phys. Chem. Solids 2017, 111, 104-109. [CrossRef]

42. Hoque, M.A.; Guzman, M.I. Photocatalytic activity: experimental features to report in heterogeneous photocatalysis. Materials 2018, 11, 1990. [CrossRef] [PubMed]

43. Schneider, J.; Bahnemann, D.W. Undesired role of sacrificial reagents in photocatalysis. J. Phys. Chem. Lett. 2013, 4, 3479-3483. [CrossRef]

44. Kamat, P.V.; Jin, S. Semiconductor photocatalysis: “tell us the complete story!". ACS Energy Lett. 2018, 3, 622-623. [CrossRef]

(C) 2019 by the authors. Licensee MDPI, Basel, Switzerland. This article is an open access article distributed under the terms and conditions of the Creative Commons Attribution (CC BY) license (http://creativecommons.org/licenses/by/4.0/). 